\title{
DE SPINOZA A HEGEL. UNA REHABILITACIÓN PRODUCTIVA DE LA NEGACIÓN
}

\author{
Hardy Neumann \\ Pontificia Universidad Católica de Valparaíso \\ hardy.neumann@pucv.cl
}

\begin{abstract}
RESUMEN / ABSTRACT
En el escrito Vorläufige Thesen zur Refomation der Philosophie, Ludwig Feuerbach atribuye a Spinoza la autoría de la filosofía especulativa. A la zaga queda Schelling, considerado por Feuerbach únicamente como el restaurador de la misma. En la secuencia establecida por éste, Hegel sería, por su parte, solo un elemento más en la constitución de la filosofía especulativa, aunque tiene el mérito de completar tal sistema de pensamiento. En el presente artículo pretendo determinar en qué medida el autor de esta filosofía se halla presente en el que la consuma. Esbozaré la forma y grado de esa presencia poniendo el foco en un aspecto nuclear, que, al mismo tiempo, servirá de guía del trabajo aquí propuesto: la negación ${ }^{1}$.
\end{abstract}

Palabras clave: Spinoza, Hegel, determinatio, negatio, negación.

\section{From Spinoza to Hegel. A productive rehabilitation of the DENIAL}

Ludwig Feuerbach gives Spinoza the credit of authorship of speculative philosophy. Lagging behind is, therefore, Schelling, considered by Feuerbach as the restorer (Widerhersteller) of the same. In the sequence established by Feuerbach, Hegel would be, for his part, just a further element in speculative philosophy's constitution, nevertheless, having the considerable merit of accomplishing such system of thought. In this paper, my aim is to determine to what extent the author of this philosophy is present in the one who fulfills it. I will outline the shape and extent of that presence by placing the focus on a nuclear aspect, which, at the same time serves here as a guide for my proposal: denial.

KEYWORDS: Spinoza, Hegel, determinatio, negatio, negation.

\section{Origen de la fórmula omnis determinatio est negatio en Spinoza}

Da Hel tiene para con Spinoza palabras que no son solo de admiración, sino que se hallan insertas en su propio programa, p. ej., aquella de que "si se comienza

Estas ideas de Feuerbach pueden verse en Entwürfe zu einer neuen Philosophie (1996), p. 3. En la terminología de Feuerbach, Spinoza es el Urheber de la filosofía especulativa; Schelling su Wiederhersteller; Hegel, su Vollender (cfr. loc. cit., p. 3). 
a filosofar, hay que ser primero spinozista" (Hegel (1969-1971) VGPh. W, XX, p. $165)^{2}$. Declaraciones de este tenor revelan, sin embargo, solamente un aspecto de una posible valoración. El propio Hegel recuerda que Lessing decía de su época que "la gente trata a Spinoza como un perro muerto" (Hegel (1969-1971), Enzikl. (1830) W, VIII, p. 22) ${ }^{3}$. Esa forma de (mal)trato debería también decirse a veces del propio Hegel ${ }^{4}$. En el Differenzschrift (1801) Hegel declara que "ningún comienzo de una filosofía puede lucir peor que aquel que se hace con una definición, como en Spinoza" [...] (Hegel (1969-1971), W, II, p. 37) , diatriba que recae obviamente sobre la Ética. En otro pasaje de ese mismo texto hay nuevamente palabras elogiosas, pero no exentas de cierta superioridad: "Cuando la razón se ha purificado de la subjetividad del reflexionar, entonces puede recibir su justa apreciación aquella ingenuidad de Spinoza, según la cual la filosofía comienza con la filosofía misma y la razón deja entrar en escena con igual inmediatez una antinomia" (Hegel (1969-1971), W, II, p. 37)

Formulaciones de este tipo se repiten, pues referencias al filósofo de Amsterdam hay muchas, especialmente en la obra temprana de Hegel. Pero entre esas ideas hay un pensamiento que en la relación Spinoza-Hegel sea, probablemente, el más conocido, y que se expresa en la fórmula habitual: omnis determinatio est negatio, "toda determinación es negación". Se trata ciertamente de una idea central y fecunda, pero, por lo mismo, más difícil de sopesar en su justo sentido e impacto así como en lo que toca al lugar que ocupa en el pensamiento spinoziano y en el propio sistema de Hegel.

Hegel volvió la expresión omnis determinatio est negatio a tal punto productiva para su propio programa, que hoy se la recuerda casi exclusivamente en la versión con que él la hizo famosa, dejando la impresión de que ese enunciado podría leerse directamente en la ontología de la Ética. Pero, en verdad, aunque muchas veces se la enseñe, sin más, con esa pretensión principial y universal, la frase no es localizable con ese tenor en Spinoza. Ya este hecho debería hacer sospechar de su centralidad ontológica o al menos de la versión con que se popularizó. En verdad, fue el propio

2 wenn man anfängt zu philosophieren, so muß man zuerst Spinozist sein.

3 Lessing sagte zu seiner Zeit: die Leute gehen mit Spinoza wie mit einem toten Hunde um; man kann nicht sagen, daß in neuerer Zeit mit dem Spinozismus und dann überhaupt mit spekulativer Philosophie besser umgegangen werde.

$4 \quad$ El maltrato no se refiere ante todo a un juicio duro y eventualmente injusto en torno a Spinoza, sino, como lo muestra claramente B. Sandkaulen, a la serie de transformaciones, lecturas y niveles discursivos con que Hegel opera en su propia obra al momento de abordar a Spinoza, especialmente en lo que concierne al concepto de substancia (cf. Sandkaulen 2007, en especial, pp. 246-252).

$5 \quad$ Kein Anfang einer Philosophie kann ein schlechteres Aussehen haben als der Anfang mit einer Definition wie bei Spinoza [...].

$6 \quad$ Wenn aber die Vernunft von der Subjektivität des Reflektierens sich gereinigt hat, so kann auch jene Einfalt Spinozas, welche die Philosophie mit der Philosophie selbst anfängt und die Vernunft gleich unmittelbar mit einer Antinomie auftreten läßt, gehörig geschäzt werden. 
Hegel, a partir de Jacobi (1743-1819)7 y de Franz von Baader (1765-1841) (cfr. Hübener 1975 , p. 500), quien contribuyó decisivamente a la fijación y perduración de la frase en esa adaptación ${ }^{8}$.

Lo más probable es que la idea en comento tenga su origen en una carta de Spinoza a su amigo Jarig Jelles, fechada el 2 de junio de 1674. El pasaje pertinente de la carta, apreciable como cantera desde la que se elabora el contenido del material que Hegel hace famoso, es el siguiente:

En cuanto a que la figura es una negación y no algo positivo, está claro que la materia toda, considerada indefinidamente, no puede tener figura alguna y que la figura tan sólo se halla en los cuerpos finitos y limitados. Quien dice, por consiguiente, que comprende una figura, muestra precisamente con ello que comprende una cosa limitada y de qué manera está limitada. Esta determinación no pertenece, por tanto, a la cosa, según su ser; por el contrario, es su no ser. De ahí que, como la figura no es sino determinación y determinación, negación, [la figura] no podrá ser otra cosa que negación (Spinoza, Correspondencia 1988, p. 309).

Conviene tener presente -(solo inpuncto) - el pasaje en su lengua original, pues dicha frase se popularizó en latín:

Haec ergo determinatio ad rem juxta suum esse non pertinet: sed econtra est ejus non esse. Quia ergo figura non aliud, quam determinatio, et determinatio negatio est; non poterit aliud quid, quam negatio, esse.

En la carta se observa la importancia que gana para sí la negación, de manera independiente. Este rasgo es notable. En efecto, se trata de una novedad que rompe al menos con buena parte de la tradición filosófica, que ponía la negación en el ámbito del contraconcepto del ser y que destacaba como elemento positivo únicamente la realitas. Curiosamente, sin embargo, la idea de negación, como algo que no se reduce a servir de elemento contradictorio del ser, se hallaba larvadamente en esa misma tradición. Su presencia "tras el telón" puede rastrearse hasta la filosofía antigua, especialmente hasta Platón y Aristóteles. La incursión del no-ser en el ámbito del ser es una posibilidad que hace circular su efecto no solo en el mutuo entrecruzamiento de ideas ${ }^{9}$ (mediante el cual se origina incluso el discurso) (Sofista 259e), sino en el propio entrelazamiento de nombres y verbos $(\mathrm{So} /, 262 \mathrm{~d} \text {. })^{10}$. El extranjero se ve forzado a aceptar que "el no-ser

7 Con la tesis de que la filosofía de Spinoza sería la única filosofía consecuente desató Jacobi el famoso Spinozastreit o Atheismusstreit.

8 Hegel se habría encontrado con la filosofía de Spinoza al menos ya en la época final de su etapa de colegio, en la recensión de un escrito de Rehberg (cfr. Jäschke (2010,) Hegel Handbuch, p. 13).

tèn alléloon tôn eidòn symplokèn. symplékoon tà rémata tô̂s onómasi. 
en cierto modo es y que el ser, por otra parte, de alguna manera no es" ( Sof., 241d.) ${ }^{11}$, cometiendo, así, parricidio contra el padre Parménides.

Pero no solo la negación ha parecido estar sometida a un destino marginal. En efecto, al menos la afirmación lógica ha padecido también, aunque más moderadamente, una suerte de ostracismo filosófico. La afirmación y la negación tendrían efectos solo en el plano del pensamiento y no el de las cosas, de acuerdo con Aristóteles (cfr. Met. E, 4 1027b 25-26). Pero la peor parte se la llevó la negación, cuando en la tradición que sigue a Aristóteles se vieron ambas reducidas en su posible rendimiento filosófico, pues "la negación no pone algo ni determina de suyo un sujeto" (S. Th. I, q. 17 a. 4 in c.) $)^{12}$. Un autor renacentista como Trombetta (1436-1517) (que no es precisamente de la línea de Tomás) mantiene esta postura. Para él, la negatio extra genus, que es la negación en sí misma, distinta de la negatio simplex o pura, tiene ser tan solo por obra del intelecto ${ }^{13}$ (cfr. Trombeta, Opus in Metaphysicam Aristotelis Paduae in Thomistas discussum, 1502, I. 12, q. 6, f. 91 vb., citado por Hübener 1975, p. 114). Y ya entrada la Modernidad, aún Mastrius de Meldula, el "escotista, por cierto, más importante del siglo 17" (Hübener 1975, p. 106) decía que ni "las negaciones ni las privaciones son dignas de ser consideradas directa y per se" (Hübener 1975, p. 106).

Es interesante observar que en el desarrollo del fenómeno de la negación, pese a todo "aparente nuevo comienzo del filosofar" (Heidegger 1986, ST, pp. 24-25), la postura de Descartes sigue, en este punto, dependiendo de la escolástica. Incluso, a través de la escolástica racionalista de Wolff se mantiene hasta el mismo Kant del período crítico. Con todo, conviene precisar que Descartes también escribía que [...] limitatio, quafinitum differt ab infinito, est non ens sive negatio entis... (Oeuvres, AT, 3, p. 426) y que, para Leibniz, las creaturas son reducidas o limitadas porque participan del principio de la negación o de la nada. Elles sont bornees ou imparfaites par le principe de la Negation ou de Neant qu'elles renferment (Leibniz 1948, Textes inédits, ed. Grua, Paris, t. 1, p. 364). Pero, wirkungsgeschichtlich y oficialmente, para todos ellos vale que la negación solo es comprensible desde la afirmación o la realitas, a pesar de que Kant haya distinguido claramente entre realitas y esse ("ser no es de modo alguno un predicado real") ( $\mathrm{KrV}$, A 598/B 626), idea que, mutatis mutandis, se hallaba ya en la fórmula aristotélica: "estar-siendo no es en absoluto ousid" (Anal. Post, 92 b 13-14) ${ }^{14}$. Digno de nota es que, si se atiende a su legado cartesiano, Spinoza podría simplemente haberse mantenido en esta forma de entender la realitas. Sin embargo, no fue así, o, al menos, no del todo. Spinoza, quien constituye justamente una (o la) excepción a esta idea de buena parte de la tradición filosófica, destaca la calidad autónoma de la negación, aunque para Hegel esto haya sido aún limitado, en razón de su carácter unilateral (einseitig), como veremos.

11 kaì biázesthai tó te mè ón hos ésti katá ti kaì tò on âu pálin ouk ésti pee.

12 negatio neque ponit aliquid, neque determinat sibi aliquod subiectum.

13 habet esse per opus intellectus tantum.

14 tò de ênai oúk ousía oudení. Ver tb. De Interpret., 3, 16 b 20-25. 
La idea de un rendimiento propio de la negación no es, por cierto, un rasgo difundido ni presente en toda la obra spinoziana, pero sí en algunos pasajes clave de la misma. Para mostrarlo hay que recurrir a dos fuentes: la primera es la ya mencionada carta a Jarig Jelles. A este respecto, aunque pareciera que el intérprete logra ver la idea spinoziana de la determinatio-negatio únicamente en la carta a Jelles, el lector atento podrá constatar que lo pensado en esa frase está claramente contenido y, por consiguiente, ocupando un lugar de primer orden, en la obra fundamental de Spinoza, en la Ética, exactamente, en el Escolio I de la proposición VIII de la primapars: de Deo. Tal es, además, la segunda fuente. Se trata allí de un lugar eminente en el marco fundacional de esa obra y, en consecuencia, gravitante para la arquitectura, despliegue e impacto de la misma. La I parte de la Ética contiene, como se sabe, la ontología spinoziana, y la frase hace su aparición al intentar demostrarse allí la necesidad de la infinitud de la substancia ${ }^{15}$. Spinoza escribe a este respecto:

puesto que ser finito es, en verdad, una negación parcial, e infinito la afirmación absoluta de la existencia de alguna naturaleza, se sigue, por tanto, de la sola proposición 7 que toda substancia debe ser infinita (Ética, prop. VIII, Escolio I) ${ }^{16}$.

El interés directo de Spinoza es demostrar de qué manera la prop. 7 conduce necesariamente a la infinitud de toda substancia. Pero más allá de esta circunstancia inmediata, puede observarse que en la referencia a la existencia infinita de la substancia se incluye, como horizonte último de comprensión, la finitud de la existencia, la existencia finita. En efecto, Spinoza concibe positivamente la infinitud o, si se quiere, concibe el verdadero cariz de la existencia desde la infinitud misma. Dicho aún de otra manera: para Spinoza la infinitud es solo denominativamente negación, no realiter. Con la semántica formal de Tugendhat, diríamos que infinitud es aquí un término que solo gramaticalmente, pero semánticamente funciona como una negación. In re, "in-finito" no significa negación, aunque terminológicamente lo sea. Estas distinciones son la condición indispensable para comprender que la determinatio est negatio, según la carta a Jelles, o que el ser infinito es afirmación absoluta de la existencia, o sea, que la finitud es ciertamente afirmación de la existencia, pero solo ex parte, parcialmente, y que, por tanto, ella está necesariamente traspasada por la negación. Recordemos: Ser finito no es tanto afirmar una determinación cuanto afirmar una negación, aunque parcial, de la existencia, según el Escolio I aludido. Si la negación absoluta de la existencia daría justamente pie a la nada, la afirmación absoluta de la existencia daría lugar, a su turno, a la negación total de la parcialidad de la negación que toda cosa lleva consigo, por ser algo determinado, dando por resultado la infinitud, esto es, la no-finitud, la no-determinación. Este conjunto de ideas se vuelve aún más paradójico si se tiene presente que se trata en esto de una filosofía en que el ser mismo se concibe, siguiendo, en lo inmediato, a Descartes, como realitas. En esa línea está la afirmación spinoziana en la proposición IX de la Primera

15 Posteriormente, desde el escolio 1 de la proposición XIV, la una y única substancia.

16 Cum finitum esse revera sit ex parte negatio, et infinitum absoluta affirmatio existentiae alicujus naturae, sequitur ergo ex sola prop. 7 omnem substantiam debere esse infinitam. 
Parte de la Ética: "Cuanto más realidad o ser tiene una cosa, tantos más atributos le competen"17.

Finitud, pues, no es tan solo negación a secas; la finitud está al servicio de un modo como la existencia se especifica, a saber, como existencia determinada. Una existencia determinada no es ni la tiene tan solo una determinada existencia, sino aquella que en su afirmación o posición lleva consigo la negación, a saber, la negación de lo infinito. Pero esa negación de lo infinito por parte de lo finito en nada disminuye el ser de lo infinito, no le afecta, pues "el ser determinado y finito no es nada en sí mismo, no es nada en él mismo y por él mismo, pues todo lo que es lo es por lo infinito, e. d. por la substancia absoluta, la única que es" (Robitaille 2007, p. 26). El ser que posee lo finito es, podría decirse, prestado, subsidiario y sucedáneo. Esta substancia infinita, por ser absoluta determinación, afirmación ab-suelta de la existencia, no lleva consigo la traza limitativa, propia de la negación; negación que, a su turno, sí es necesariamente la carga de una existencia finita. Ésta, junto con afirmar el peculiar contenido que la determina en la existencia, porque le pertenece de suyo, afirma desde ese su contenido determinado su propia negación, o sea, se abre negadoramente (sit venia verbo) a todo lo que no es ella. Lo finito es positiva afirmación de la negación de sí y en sí misma en tanto que afirmada. Spinoza responde, así, a la pregunta por el origen de la negación. Ese origen está en la realidad misma o determinación de una cosa.

Puede sostenerse, entonces, que en Spinoza infinitud no es simple negación de la finitud, omnis substantia est necessario infinita, aunque in-finito sea efectivamente negación de lo finito. Mientras que la proposición VIII, como tal, pone el énfasis en la existencia infinita de la substancia, el escolio aludido pone el acento en la negación misma que toda determinación lleva consigo; obsérvese, decimos: "que toda determinación lleva consigo", vale decir, lo positivo como tal está internamente teñido de negación y la porta. Es verdad que casi intuitivamente comprendemos que lo negativo es limitación, en este caso de la existencia, más exactamente de la infinita existencia de la substancia, pero aquí no se trata sino tangencialmente de esto. Lo que está en juego es el hecho de que la determinación lleva en su propio seno la positividad del ser y la negatividad del no-ser, pero esto segundo se lo arrastra en virtud de la determinación como tal.

2. Recepción y transformación de la determinatio-negatio en las Lecciones sobre la Historia de la Filosofía y en la Ciencia de la Lógica

\subsection{La carta a Jarig Jelles y las observaciones de Hegel}

Hegel conocía bien la obra de Spinoza. En el marco de la fuerte recepción por el Spinozastreit o Atheismusstreit, llegó incluso a colaborar en una nueva SpinozaAusgabe dirigida por su amigo de Jena, Heinrich Eberhard Gottlob Paulus, comparando 
traducciones francesas. En el caso que nos ocupa, se observa que conoce a fondo la carta en cuestión. Las observaciones que efectúa en sus Lecciones sobre la Historia de la Filosofía, en el acápite dedicado a Spinoza, así como los comentarios y la toma de posición al respecto, echan de ver que no otro era el origen de esas ideas.

En esas Lecciones, Hegel comienza diciendo que Spinoza es un punto principal (Hauptpunkt) de la filosofía moderna, algo que también expresa de Descartes. Pero mientras que éste es "héroe del pensamiento" (Hegel (1969-1971), VGPh, W, XX, p. 123), Spinoza es condición de posibilidad de toda filosofía. Recordemos: "spinozismo o ninguna filosofía". Luego agrega, más sereno, ideas desbordantes en consecuencias:

Spinoza tiene la gran afirmación: toda determinación es una negación. Lo determinado es lo finito; ahora bien, de todo, también del pensamiento (en contraposición a la extensión), puede mostrarse que es [algo] determinado, por tanto, que incluye en sí negación; lo esencial de ello descansa en la negación. Puesto que únicamente Dios es lo positivo, lo afirmativo, todo lo demás es sólo modificación, no un ente en y por sí mismo; así, sólo Dios es la substancia. Jacobi tenía, por ende, razón. La determinación simple (la negación pertenece a la forma) es un otro frente a la absoluta determinidad, negatividad, forma. La verdadera afirmación es la negación de la forma; esta es la forma absoluta. El derrotero de Spinoza es correcto; pero la frase aislada es falsa, en la medida en que expresa únicamente un lado de la negación. De acuerdo con el otro lado, la negación es la negación de la negación y, de ese modo, afirmación (Hegel, (1969-1971), VGPh, W, XX, p. 164) ${ }^{18}$.

Hegel retoma la idea central de la carta en lo que concierne a la figura, en cuanto ella está de suyo permeada de negación. Pero lejos de reducirse la negación a mera propiedad característica solo de la figura, Hegel universaliza la idea de que la determinación, que la figura implica, es una negación. De allí la fórmula con cuantificador universal omnis determinatio est negatio ${ }^{19}$. ¿Pero cómo puede la figura implicar negación? Para hacerlo ostensible, Hegel argumenta que de todo, tanto del pensamiento como de la extensión, puede mostrarse que incluye negación en tanto se trata de algo determinado.

Spinoza ist Hauptpunkt der modernen Philosophie: entweder Spinozismus oder keine Philosophie. Spinoza hat den großen Satz: Allie Bestimmung ist eine Negation. Das Bestimmte ist das Endliche; nun kann von allem, auch vom Denken (im Gegensatz zur Ausdehnung) gezeigt werden, daß es ein Bestimmtes ist, also Negation in sich schließt; sein Wesentliches beruht auf Negation. Weil Gott nur das Positive, Affirmative ist, so ist allies andere nur Modifikation, nicht an und für sich Seiendes; so ist nur Gott die Substanz. So hat Jacobi recht. Die einfache Determination, Bestimmung (Negation gehört zur Form) ist ein Anderes gegen die absolute Bestimmtheit, Negativität, Form. Die wahrhafte Affirmation ist die Negation der Form; das ist die absolute Form. Der Gang Spinozas ist richtig; doch ist der einzelne Satz falsch, indem er nur eine Seite der Negation ausdrückt. Nach der andern Seite ist die Negation Negation der Negation und dadurch Affirmation.

19 Hegel reproduce, primero en alemán, pero ya de modo universal, la frase de Spinoza. Más abajo le confiere la conocida versión: omnis determinatio est negatio (Hegel (1969-1971), $V G P h, \mathrm{~W}, \mathrm{XX}, \mathrm{p} .165)$. 
Pero luego, con las explicaciones que siguen, Hegel motiva un nuevo giro en la historia y comprensión del concepto de negación. En efecto, si ya Spinoza había provocado una fisura en la monolítica realitas al introducir en ella la negación, en virtud de la determinación que supone, Hegel, tomando a Spinoza como el que pone a su disposición el recurso de la determinatio-negatio, se enfrenta a otra idea que también era un pilar clásico: la idea de forma. En todo caso, tampoco en ello se encuentra ausente el propio Spinoza, pues éste, según se lee en la carta a Jelles, indica que "como la figura no es más que determinación y determinación es negación, ella no podrá ser otra cosa sino negación” (Spinoza 1985, Correspondencia, p. 309) ${ }^{20}$.

Pero Hegel hace explícitas las consecuencias, lleva éstas aún más lejos, atreviéndose a señalar en su exposición de Spinoza que "la negación pertenece a la forma" (Hegel 1969-1971, VGPh, W, XX, p. 164). Claramente hay allí un nuevo enfrentamiento con la tradición, especialmente la aristotélica. No es posible ya dar cabida al principio ontológico fundamental, de acuerdo con el cual "la forma da el ser" (forma dat esse) $)^{21}$, la forma no es principio de actualización, elemento determinante, frente a la materia, sino, incluso más, "la determinación simple [...] es un otro frente a la absoluta determinidad, negatividad, forma" (Hegel, 1969-1971, VGPh, W, XX, p. 164). La absoluta determinidad es la realidad absoluta de Dios, la substancia spinoziana. Pero, observemos, la determinación simple (no la absoluta) es para Hegel negatividad, sin rodeos, esto es, forma. La inversión que lleva a cabo transforma en este punto los principios nucleares de la filosofía clásica, concluyendo que "la verdadera afirmación es la negación de la forma; esta es la forma absoluta" (Hegel, 1969-1971, VGPh, W, XX, p. 164). Es mérito, a mi juicio, de Wolfgang Hübener haber destacado la importancia de esta idea descubriendo el gozne entre Spinoza y Hegel, al precisar que:

el carácter revolucionario del giro spinozista de este pensamiento de la limitación llega a ser claro recién a partir de una observación marginal de Hegel, que es el hilo conductor oculto de su interpretación de Spinoza: 'Negación pertenece a la forma'. Es cierto que las explicaciones de Spinoza en torno a la proposición determinationegatiopresuponen históricamente el rechazo de las formas substanciales de los peripatéticos. Pero si se cuenta también entre lo formal, en sentido amplio, a los substitutos cualitativos formales de la mecánica, es imposible que se pase por alto el quiebre con la antigua metafísica de la forma, según la cual toda determinación formal está del lado de la actualidad que dota de ser (Hübener 1975, p. 500).

En todo caso, Hegel está lejos de rendirse totalmente al planteamiento spinoziano. $\mathrm{Su}$ saludo al descubrimiento del rol positivo de la negación es, por supuesto, claro. Por eso rubrica en sus lecciones que "el derrotero de Spinoza es correcto", pero no tiene empacho en añadir que "la frase aislada es falsa". ¿Y por qué es falsa? Es falsa, "en la

Quia ergo figura non aliud, quam determinado, et determinado negatio est; non poterit aliud quid, quam negatio, esse.

21 Tomás de Aquino sostenía: prima perfectio est forma uniuscuiusque, per quam habet esse; unde ab ea nulla res destituitur dum manet (De veritate, 1, 10 ad. 3). 
medida en que expresa únicamente un lado de la negación" (Hegel 1969-1971, VGPh, W, XX, p. 164). Ese pensamiento es, por lo tanto, también deficiente. Y esa deficiencia se echa de ver justo en su falta de integración a otros momentos. La frase es falsa, no porque esté mal construida, sino porque el elemento de pensamiento que contiene no ha sido puesto articuladamente en el todo. La determinación como negación, incluso universalizada y así retocada por el propio Hegel, permanece en su unilateralidad. Le falta el otro lado, a saber, que "la negación es la negación de la negación y, de ese modo, afirmación". Incluso del propio texto de las Lecciones se colige que Hegel echa de menos en Spinoza un elemento de primer orden: a éste le faltó lo racional, das Vernünftige. Como sabemos, lo racional se modula diversamente. Aquella modalidad a la que se refiere Hegel aquí y que se echa en falta, es la de lo negativo racional, que, como momento propiamente dialéctico, expresa lo propio de la razón, en cuanto eso racional se identifica con la contradicción (Widerspruch), que supone, evidentemente, como condición de su despliegue, la negación como tal. Recordemos que, para Hegel, la negación es lo negativo racional, segundo estadio junto a la tesis y la síntesis. Como momento de la razón, el entendimiento no resiste la contradicción: "esta contradicción -dice Hegel- no es soportable por el entendimiento" (Hegel (1969-1971), VGPh, W, XX, p. 164). La contradicción es, ya desde la Philosophische Enzyklopadie für die Oberklasse -idea refrendada en diversos pasajes de la Enciclopedia de las ciencias filosóficas (1830)- el lado negativo racional de lo lógico ${ }^{22}$, vale decir, la negación de la tesis o posición.

\subsection{En la Ciencia de la Lógica y en La Enciclopedia}

Las ideas expuestas se reflejan especulativamente de manera aún más compleja y elaborada en la Ciencia de la Lógica y en La Enciclopedia. Seguiremos aquí, muy sumariamente, la valoración y aprovechamiento de la frase en la Ciencia de la Lógica, recurriendo a las dos ediciones, según sea preciso. La frase está llamada a ocupar un lugar de relevancia en la doctrina del ser, específicamente en una nota a propósito de la cualidad como momento de la existencia (Dasein), en el cuerpo mismo del texto que aborda a la realidad.

Al ser incorporada al sistema, la determinado qua negatio recibe la siguiente formulación: "la determinidad es la negación en cuanto puesta afirmativamente" (1812). Esa proposición, de "infinita importancia" (como se dice en 1812) o de "absoluta importancia" (como se dice en 1832), es el resultado de considerar la determinidad. ¿A qué apunta esto? La determinidad es un modo de consideración propio del entendimiento

22 Ver al respecto: Nürmberger und Heidelberger Schriften (1808-1817). La idea se enmarca en el siguiente contexto explicativo del $§ 12$ de esta obra: La lógica es la ciencia del entendimiento puro y de la razón pura, de las determinaciones y leyes propias de las mismas. Lo lógico tiene, por consiguiente, tres lados: 1. El abstracto o del entendimiento, 2. El dialéctico o negativo racional, 3. El especulativo o positivo racional (cfr. Hegel (1969-1971) Phil. Enz. fdie O. (1808 ss.), W, IV, pp. 11-12). 
$\mathrm{y}$, por tanto, es natural que quede vinculada a las distinciones parcelantes que surgen de su acción. De allí que la determinidad sea, por esencia [wesentlich], límite y su fundamento sea la alteridad o ser-otro (1832). La limitación, en consecuencia, no es accidental a la determinidad, no es un acompañamiento externo y contingente, sino que le es propiamente inherente.

Pero la determinidad no solo aparece como determinidad sino que es "la negación puesta como afirmativa" (Hegel (1969-1971), WdL, HW, V, p. 121). ¿Qué quiere decir una determinidad que en tanto negación aparece puesta como afirmativa? Tengamos en cuenta la conciencia histórica de Hegel, para así poder "explicar su disposición a diferenciar el concepto de lo negativo o respectivamente de negación. Así, p. ej., el concepto de no-ser (Nichtsein) o de inexistencia (Nichtdasein) no es sinónimo de alteridad (Anderssein), [...]. Es tarea, por tanto, de la interpretación dar lugar conceptualmente a una teoría, que ponga como base de su desarrollo el variado y específico uso del concepto de negación" (Iber 1990, p. 221) ${ }^{23}$. Teniendo en cuenta esta motivación interpretativa, se hace necesario distinguir dos formas de negación en Hegel: la negación primera o negación simple y la doble negación, también llamada negatividad absoluta, todo ello bajo el abrigo de la interesante advertencia: "Lo negativo, esta expresión abstracta, tiene muchas determinaciones [,..]"24 (Hegel 1969-1971, VPhRel., W, XVI, p. 419). La primera opera como diferencia (Unterschied), como determinidad (Bestimmtheit) y como relación con otro o simplemente alteridad o ser-otro (Andersheit). La negación primera o simple da lugar a la negación determinada. Como ese tipo de negación provoca en su resultado la determinidad (Bestimmtheit), puede decirse que ella elimina la indeterminidad superándola (aufhebt). Esta negación simple no se confunde ni con la Verneinung, que es la negación proposicional, ni con la negación abstracta, que es negación exterior, cuyo resultado es más bien un no resultado; ese resultado es solo la falta de determinación, su resultado es nada en el sentido de nada determinado. Iber añade a este respecto lo siguiente:

Importante para el sentido primario de la negación en la Ciencia de la Lógica no es, sin embargo, la cancelación [Aufhebung] en el sentido de la eliminación [Elimination], sino cancelación en el sentido de diferenciación. El significado fundamental del concepto hegeliano de negación es el de distinguir, diferenciar, delimitar o determinar, tal como ellos quedan expresados en la fórmula spinoziana citada, pero al mismo tiempo transformada por Hegel, 'omnis determinatio est negado' (Iber 1990, p. 222).

Pues bien, esta es la razón, a mi juicio, de que cuando Hegel, en la Ciencia de la Lógica, introduce la famosa fórmula spinoziana, ésta vaya interpretativamente precedida por

23 El mismo Iber también dice: "El concepto hegeliano de la negación primera o simple está orientado, ya por el concepto de determinidad de la filosofía spinozista (omnis determinatio est negatio), ya por el concepto de heterótes de la filosofía platónica, que él somete al mismo tiempo a una cierta interpretación ontológico crítica" (Iber 1990, p. 223).

Das Negative, dieser abstrakte Ausdruck, hat sehr viele Bestimmungen. 
la declaración: "la determinidad es negación en cuanto puesta afirmativamente". La determinidad, que terminológicamente es en Hegel, hóros, no es simplemente negación, en el sentido de mera Andersheit, ser-otro o alteridad. Si así fuese, Hegel habría permanecido preso de la heterótes platónica, concepto del que, por otra parte, es ciertamente deudor, y cuyo rastro se aprecia todavía en el pasaje spinoziano en la versión de 1812, para desaparecer en la de 1832. La determinidad es negación en cuanto puesta afirmativamente, o sea, con Spinoza, gracias a la autoafirmación misma o identidad, por así decirlo, que le corresponde a la cosa, y, en tal sentido, siempre con Spinoza, en tanto que determinada, pero, a la vez, tomando distancia de él, en cuanto que no se trata tampoco de la negación pura o del no-ser. Hegel deja en claro que desde el otro lado, o sea, el negativo racional y, por tanto, traspasada ya así de especulación, la negación es negación de la negación y, de ese modo, afirmación (cfr. Hegel 19691971, VGPh, W, XX, p. 164).

Dado que está en juego una caracterización de la negación como puesta afirmativamente, podría pensarse que se trata de una negación pura, que haría a la negación equivalente al no-ser, al modo de los anacolutos iniciales de la Ciencia de la lógica: "ser, puro ser, sin ninguna determinación ulterior" (Hegel 1969-1971, WdL, W, V, p. 82 ${ }^{25}$. En la formulación ya elaborada de la frase de Spinoza, Hegel hace explícita la negación que estaba pensada en la determinatio. De allí que su versión de esa proposición fundamental diga derechamente que la determinación es la negación. El solo hecho de que la negación sea puesta logra que ella quede mostrada como tal; la determinatio es una negatio encubierta, el embozo de la negación le es arrebatado a la determinación para brillar en la luz de la afirmación. La negación, propia de la determinación, es puesta positiva, afirmativamente por Hegel. El lado de lo negativo en la determinación queda puesto como tal, o sea afirmado en tanto que negación.

\section{Conclusión}

Para Spinoza, el absoluto es ciertamente la substancia. Una relación entre substancia y modos no es posible, pues éstos se explican tanto en su ser como en su ser-concebidos por la substancia misma (Spinoza, Ética, I, def. III). La distancia que separa a la substancia y a los modos es insuperable, a tal punto que, en propiedad, no es admisible hablar de distancia. La manera en que, a mi juicio, Spinoza expresa que la substancia supera toda determinación, es aquella contenida en la segunda parte de la explicación de la definición VI (Dios), en paralelo con la def. II (finitud genérica), pues a la esencia de lo que es absolutamente infinito pertenece todo cuanto expresa su esencia, y no implica negación alguna ${ }^{26}$. Lo absoluto está más allá de toda determinación y esto

25 Sein, reines Sein, -ohne allie weitere Bestimmung.

26 quod autem absolute infinitum est, ad ejus essentiam pertinet, quicquid essentiam exprimit, et negationem nullam involvit. 
quiere decir, como agudamente apunta Taylor en este punto, que la substancia está más allá incluso de la negación como tal (cfr. Taylor 1983, p. 367). Vale decir, también la negación se incluye entre lo superado por la substancia absoluta en Spinoza. Pues bien, pienso que justo eso es algo que Hegel no quiere ni acepta; para él no hay un absoluto, una substancia, sin negación. Pero ésta, la negación, debe ser afirmada no solo como simple explicitación de la determinidad -que es la idea de Spinoza que Hegel pone al descubierto-, sino como negación negante. Hegel dice de la negación qua negación o negación como tal, o sea abstracta, vacía, que es formlose Abstraktion, lo que quiere decir que así considerada será siempre einseitig, unilateral (cfr. Hegel 1968-1971, WdL, $\mathrm{W}, \mathrm{V}, \mathrm{p} .121)^{27}$. Curiosamente esta unilateralidad constituye la médula del dualismo spinoziano, pues las determinaciones de su substancia, consideradas desde la negación, que ahora Hegel introduce y gana, no surgen o, mejor, no pueden surgir de la misma substancia, a fuer de hallarse sin motivación dialéctico-especulativa para llevar a cabo su marcha hacia sí misma. Dicho de otra manera, la substancia no puede relacionarse con sus modos, y si lo hace, esto solo puede ocurrir exteriormente. Los modos, como determinaciones, son negaciones que jamás afectan a la substancia, pues ésta trasciende toda determinación de finitud genérica; es no solo in-finita en algún género, sino absolutamente, simpliciter (Spinoza, Ética, defs. II y VI) ${ }^{28}$.

27 Cf. Una buena explicación del carácter abstracto unilateral del primer momento lo ofrece Hegel en Grundlinien der Philosophie des Rechts (1821, 1833). Allí puede leerse: "Este segundo momento de la determinación es asimismo negatividad, eliminación superadora que conserva, tal como lo primero -a saber, él es la eliminación conservadora superadora de la primera negatividad abstracta-. Tal como lo particular en general está contenido en lo general, así este segundo momento está contenido ya en el primero y solo es un poner aquello que lo primero es ya en sí; -el primer momento, en cuanto primero para sí, no es la verdadera infinitud o universalidad concreta, el concepto,-- sino solo un algo determinado, unilateral; vale decir, porque es la abstracción de toda determinación, él mismo no es sin la determinación; y ser en cuanto abstracto, unilateral, constituye su determinación, imperfección y finitud“"(Hegel 1968-1971, GrPhRechts, W, VII, p. 52). Holístico, se podría decir, en cambio, es lo que se determina racional y completamente y, por eso, puede recibir el nombre de "concreto", precisamente porque ha con-crecido, ha crecido devinientemente junto con [...]. A diferencia de elementos aislados, ver Enz., § 164.

28 El latín expresa claramente el modo como la determinación implica no solo perfilamiento de la realidad de una cosa, sino, a la vez, sus contornos, en el sentido de que ella termina en alguna parte, que tiene terminaciones, que está acabada. Esto se percibe muy bien en la definición que Spinoza ofrece de "cosa finita en su género" (res in suo genere finita), a saber: "se llama cosa finita aquella que puede ser terminada [...] por otra de su misma naturaleza" (ea res dicitur finita, quae alia ejusdem naturae terminari potest) (Spinoza, Ética, def. II) Acabar una cosa no solo es completarla sino, a la vez, limitarla o reducirla a las posibilidades ofrecidas en ese acto de acabamiento. 
Referencias bibliográficas

FUENTES

Aristóteles (1995), “Analíticos Posteriores”, Tratados de Lógica (Órganon), II. Madrid: Gredos.

"De Interpretatione" (1995), Tratados de Lógica (Órganon), II. Madrid: Gredos.

Hegel, Georg Wilhelm Friedrich (1969-1971), VGPh, Vorlesungen über die Geschichte der Philosophie III. Werke in zwanzig Bänden. Band XX. TheorieWerkausgabe. Redaktion: Eva Moldenhauer und Karl Markus Michel. Frankfurt am Main.

(1969-1971), Enzikl, Enzyklopädie der philosophischen Wissenschaften im Grundrisse (1830). Werke in zwanzig Bänden, Band VIII. TheorieWerkausgabe. Redaktion: Eva Moldenhauer und Karl Markus Michel. Frankfurt am Main.

(1969-1971), Diff. Differenz des Fichte'schen und Schelling'schen System der Philosophie. Jenaer kritische Schriften. Werke in zwanzig Bänden, Band II. Theorie-Werkausgabe. Redaktion: Eva Moldenhauer und Karl Markus Michel. Frankfurt am Main.

(1969-1971), Phil. Enz. f. die O. Nürnberger und Heidelberger Schriften (1808-1817). Werke in zwanzig Bänden, Band IV. Theorie-Werkausgabe. Redaktion: Eva Moldenhauer und Karl Markus Michel. Frankfurt am Main.

(1969-1971), GrPhR, Grundlinien der Philosophie des Rechts. Werke in zwanzig Bänden, Band VII. Theorie-Werkausgabe. Redaktion: Eva Moldenhauer und Karl Markus Michel. Frankfurt am Main.

(1969-1971), VPhR, Vorlesungen über die Philosophie der Religion, Werke in zwanzig Bänden, Band XVI. Theorie-Werkausgabe. Redaktion: Eva Moldenhauer und Karl Markus Michel. Frankfurt am Main.

(1969-1971), WdL, Wissenschaft der Logik. Werke in zwanzig Bänden, Band V. Theorie-Werkausgabe. Redaktion: Eva Moldenhauer und Karl Markus Michel. Frankfurt am Main.

Kant, Immanuel (1998), Kritik der Vernunft. F. Meiner Verlag: Hamburg.

Platón (1988), Sofista, en Diálogos, V. Madrid: Gredos.

\section{SECUNDARIAS}

Descartes, René (1899), Oeuvres. Ch. Adam et. P. Tannery (AT), Tome 3. Paris.

Feuerbach, Ludwig (1996), Entwürfe zu einer neuen Philosophie. Hamburg: Felix Meiner.

Heidegger, Martin (1986), Sein und Zeit. Tübingen: M. Niemeyer Verlag.

Hübener, Wolfgang (1975), “Zu Spinozas Satz ,omnis determinado est negatio”, en Harald Weinrich, Positionen der Negativität. München: W. Fink. 
"Die Logik der Negation als ontologisches Erkenntnismittel", Positionen der Negativitat. München: W. Fink.

Iber, Christian (1990), Metaphysik absoluter Relationalität: eine Studie zu den beiden ersten Kapiteln von Hegels Wesenslogik. Berlin, N. York: W. de Gruyter.

Jäschke, Walter (2010), Hegel Handbuch. Stuttgart: Verlag J.B Metzler.

Leibniz, Gottfried Wilhelm (1948), Textes inédits, publiés et annotés par. G. Grua, tome 1. Paris.

Robitaille, Mathieu (2007), "Hegel et le spinozisme dans les années d'Iéna”, Laval théologique et philosophique, vol. $63, \mathrm{n}^{\circ} 1$.

Sandkaulen, Birgit (2007), "Die Ontologie der Substanz, der Begriff der Subjektivität und die Faktizität des Einzelnen. Hegels reflexionslogische ,Widerlegung' der Spinozanischen Metaphysik", Internationales Jahrbuch des deutschen Idealismus = International Yearbook of German Idealism, $\mathrm{N}^{\circ}$ 5. Berlin: W. de Gruyter.

S. Thomae Aquinatis (MCMLXXVIII), Summa Theologia. I Prima Pars, Biblioteca de Autores Cristianos. Matriti.

(1964), Quaestiones Disputatate De Veritate. Roma: Marietti.

Spinoza, Benito (1987), Ética. Introducción, traducción, notas e índices de Vidal Peña. Madrid: Alianza Editorial.

(1988), Correspondencia, Carta 50. Introducción, traducción, notas e índices de Atiliano Domínguez. Alianza Editorial: Madrid.

Taylor, Charles (1983), Hegel. Frankfurt am Main: Suhrkamp. 